\title{
UMA PROPOSTA ALTERNATIVA DE PESQUISA, PÓS-GRADUAC̄̃̃O E DESENVOLVIMENTO, ESPECIALMENTE NAS CIÊNCIAS QUÍMICAS, SOBRETUDO PARA O BRASIL E O TERCEIRO MUNDO EM GERAL
}

Jaswant Rai Mahajan 
Nos trabalhos anteriores, focalizamos diversos fatores que tornam as atividades de pesquisa e desenvolvimento ( $P \& D)$ no Brasil e no Terceiro Mundo, em geral, pouco afetivas em romper o ciclo vicioso gerado por subdesenvolvimento e conseguir a emancipação do jugo oligopólico reinante no universo da Ciência e Tecnologia (C \& T) $(1,2)$. Neste trabalho, procuramos demonstrar que esse fracasso se deve também ao modelo de pesquisa e pós-graduação adotado pelas universidades dos países em desenvolvimento, uma vez que é ali que se formam os profissionais altamente qualificados e se executa a parte predominante de $P$ \& $D$ empreendida nesses países. A presente proposta visa sanar/modificar o quadro prevalecente. Para viabilizá-la, encontram-se no final deste trabalho algumas sugestões de caráter geral bem como específicas.

Até a década cinqüenta, o modelo de pós-graduação adotado pela maioria dos países era baseado no sistema europeu, especialmente germânico, que exigia uma tese original incorporando a investigação científica individual para a obtenção do título de doutor (Ph.D.). A partir dos anos sessenta, o exemplo norte-americano - que por sua vez pode ser considerado como uma evolução da influência alemã começou a despertar o interesse do mundo todo e, atualmente, é seguido tanto no Brasil como em outros países. $O$ mérito do sistema americano consiste em que o pós-graduando, além da tese doutoral ou a dissertação de mestrado, é obrigado a cursar um certo número de disciplinas avançadas e participar dos seminários, cobrindo amplamente a área escolhida, que servem de sólida formação intelectual e preparo para a investigação científica própriamente dita.

Embora estejamos de pleno acordo com esse sistema de pós-graduação para os países já desenvolvidos, acreditamos que esse modelo deva sofrer ligeiras modificações para adaptá-lo às necessidades dos países em desenvolvimento, que apresentam culturas, ambientes científicos, evolução tecnológica, realidades sócio-econômicas, infra-estrutura, etc, bem diferentes do que reinantes nos países adiantados. A falta dessa adaptação e o conspícuo desvínculo da pesquisa e pósgraduação do setor produtivo, nos países subdesenvolvidos, tem gerado certa confusão e falsas expectativas em torno das universidades, tanto da parte de docentes, discentes e pesquisadores, como de planejadores e patrocinadores de $P \& D$ e, especialmente, da parte dos em- 
presários que ainda não encontram muitos "pacotes tecnológicos" em nossas universidades.

Comentaremos primeiramente sobre a formação de recursos humanos que é tida como a tarefa principal e tradicional da Universidade. De fato, sem tais recursos não se constrói e muito menos se mantém uma civilização técnico-científica. A demanda de pessoal altamente qualificado, especialmente nos Estados Unidos, tem sido tão grande nas últimas décadas, que as próprias universidades norteamericanas, apesar de sua volumosa produção, não têm conseguido supri-la, desencadeando o fenômeno chamado de brain-drain, isto é, um fluxo de pessoal altamente qualificado das nações menos para as mais privilegiadas. Como o setor industrial norte-americano é o grande empregador de pessoal técnico-científico ( $\sim 50 \%$ do total) e executa mais do que $70 \%$ das atividades de $P \& D(1,2)$, é muito lógico que a formação de recursos humanos tem sido também um dos seus próprios objetivos. Conseqüentemente, este setor está educando/treinando, atualmente, quase o mesmo número ( $\sim 8$ milhões) de empregados que de alunos matriculados no ensino superior daquele país, gastando acima de quarenta bilhões de dólares, contra sessenta biIhões despendidos nas escolas superiores e universidades daquela nação. E aqui deve-se enfatizar que não se trata apenas de preencher lacunas do ensino superior regular, mas mormente de proporcionar profissionalismo, aperfeiçoamento e especialização para importantes tarefas de produção, gerência, organização e, inclusive, pesquisa nas tecnologias de ponta. Isso tem se tornado não apenas desejável mas igualmente necessário, uma vez que se enfrenta uma outra realidade dura e dolorosa: que mesmo as melhores universidades do mundo, apesar de sua tradição, fama, experiência e dedicação não estão mais na vanguarda e posição de liderança - mas, sim, na retaguarda do setor privado, com a defasagem de um a três anos - no que diz respeito à situação prevalecente na alta tecnologia, exemplificada pela eletrônica, computação, informática, soft-ware, etc. (3).

Em contraste, nos países do Terceiro Mundo falta o complexo industrial e, mesmo quando existe, carece de atividades de $P \& D$, como ilustrado pelo caso brasileiro. Conseqüentemente, nestas nações, exemplificando mais uma vez com nossa própria pátria, as atividades de pesquisas, na sua maioria, são praticadas nas universidades 
como um exercício de pós-graduação, tendo pouca repercussão seja no âmbito nacional ou internacional. Além disso, o mercado de trabalho para docentes/pesquisadores se restringe apenas às universidades, com pouco estímulo e apoio, tanto da parte do governo como a do setor produtivo. Daí, a Universidade do Terceiro Mundo não pode contentar-se apenas com a formação de recursos humanos, mas deve também procurar e propor saídas praticáveis, visando sanar essa situação e diminuir a excessiva dependência tecnológica que, aliás, sempre tem sido um dos objetivos dos planejadores e atualmente constitui uma das metas da Nova Universidade (4) e do III Plano Nacional de Pós-Graduação (5); porém, estes documentos não têm ainda uma proposta concreta para alcançar a meta anunciada.

Além das diversas causas da desencorajadora situação dominante no Terceiro Mundo, já apontadas anteriormente $(1,2)$, gostaríamos agora de abordar mais uma que, sendo a "vaca sagrada" no meio universitário, foi postergada, visando uma análise fria e reflexão mais profunda, uma vez que se prevê grande reação e apaixonada controvérsia, se a mesma fosse tocada. Trata-se da tradição consagrada: que as universidades devam desenvolver, principalmente, as pesquisas chamadas puras/básicas/fundamentais. Na realidade, nos países desenvolvidos, essa determinação foi uma conseqüência da evolução que ocorreu ainda no século passado, quando as universidades européias e norte-americanas concluíram que, além de ensinar e disseminar apenas o saber conhecido, elas deviam também empreender a elaboração e desenvolvimento de conhecimentos novos. Este objetivo vem sendo perseguido através da investigação científica, cujos procedimentos estão em aperfeiçoamento contínuo desde a época da Renascença. Mas, aqui, convém relembrar que, nesses países, o setor produtivo tem sido sempre dinâmico e propulsor de tecnologias e desenvolvimento, que the conferiram a sua atual denominação "países desenvolvidos"

Este, certamente, não é o caso das universidades brasileiras, que mal conseguiram emular algum modelo de pesquisa e pós-graduação européia, até os anos sessenta, quando foram obrigadas a adaptaremse à Reforma Universitária, sendo a pós-graduação definida e regulamentada pelos pareceres 977/65 e 77/69 (6a, b). O parecer 977/65 analisou, de maneira sucinta e clara, a situação de pós-graduação 
então prevalecente em nossas universidades. Gostaríamos de reproduzir, aqui, apenas algumas linhas referentes à experiência brasileira em pós-graduação: "Sendo, ainda, incipiente a nossa experiência em matéria de pós-graduação, teremos de recorrer inevitavelmente a modelos estrangeiros para criar nosso próprio sistema. $\mathrm{O}$ importante é que o modelo não seja objeto de pura cópia, mas sirva apenas de orientação. Atendendo ao que nos foi sugerido pelo aviso ministerial, tomaremos como objeto de análise a pós-graduação norte-americana, cuja sistemática já provada por uma longa experiência tem servido de inspiração a outros países" (7).

Focalizando novamente a importância outorgada à pesquisa básica/fundamental pelas universidades dos países adiantados, isso parece muito lógico e natural, uma vez que têm tradição, experiência e produção acumulada durante séculos. Estão na vanguarda e lutam para manter-se na liderança, gastando com pesquisas puras apenas uma pequena parcela da dotação total destinada às atividades de $P \& D$. No caso norte-americano, isso significa somente 6-9\% dos dispêndios totais com $P$ \& $D$ nacional. Aqui, deve-se enfatizar que, para cada dólar americano gasto nas investigações básicas, são gastos dois nas pesquisas aplicadas e mais do que cinco no desenvolvimento. E gostaríamos de ressaltar também que o total das despesas com as atividades de $P$ \& $D$ norte-americanas alcançam cifras bem avultadas, chegando ao torno de 120 bilhões de dólares, no corrente ano, e correspondendo a $2,7 \%$ do seu PNB (e $40 \%$ do PIB brasileiro!) (8). Para mera comparação, lembramos que uma quantia desta ordem é superior à soma dos gastos com $P$ \& D dos quatro outros gigantes industriais, a saber: o Japão, a França, a Alemanha Ocidental e a inglaterra, embora mantendo, aproximadamente, a mesma proporção ( 2,5\%) com o PNB desses países.

Este, certamente, não é o retrato da nossa nação que, sendo um país periférico e mal conseguindo aplicar menos que $0,5 \%$ do seu PIB em $C$ \& $T$, encontra-se, de fato, na retaguarda de $P \& D$ mundial, tanto no âmbito universitário como no setor público; e o setor privado, quase não realiza pesquisa alguma. Conseqüentemente, não se pode imitar simplesmente o modelo e sistema de pesquisa universitária das nações já desenvolvidas, onde as tarefas de pesquisas puras, aplicadas e de desenvolvimento encontram-se bem divididas entre as universidades, governo e corporações industriais. 
Desta forma, a prioridade dada à pesquisa pura nas nações do Terceiro Mundo não é uma evolução ou decorrência natural de experiências já assimiladas, mas, sim, resultado de mera doutrinação alheia ou de simples imitação, embora costumem justificar tal procedimento pela pretensa lógica de que das pesquisas puras brotam as ramificações aplicadas, que eventualmente frutificam e ingressam no setor produtivo como novos produtos, técnicas e serviços, etc. Mas é do conhecimento público que essa política, entre nós, não tem alcançado, até agora, qualquer êxito notável, nem nas etapas iniciais do esquema-modelo abaixo ilustrado.



Pelo contrário, sabe-se que a maior parte do parque industrial das nações em desenvolvimento é sustentada pelas importações, sejam de produtos manufaturados, intermediários ou de pacotes tecnológicos, e não se gera nele o know how próprio, o que é rotineiro nas nações adiantadas.

Desta forma, se, de um lado, o setor produtivo dos países em desenvolvimento não necessita ou não solicita quaisquer serviços da comunidade científica nacional, desvinculando-a da tecnologia e dos aspectos sócio-econômicos da Ciência e da nação, do outro, raramente encontra-se um governo do Terceiro Mundo que realmente tenha convocado ou confiado aos cientistas locais o desenvolvimento de um projeto, seja de $C \& T$ ou de bem-estar e de progresso nacional. Conseqüentemente, para a maioria dos cientistas e pesquisadores destas nações, sobram apenas "anjos" ou "diabos" para namorar - os primeiros, representados pelas pesquisas chamadas puras (e, melhor ainda, aquelas que estão associadas aos grupos e/ou clubes internacionais) e os últimos, pelas lutas contra efeitos nocivos, como poluição ambiental e exploração técnico-científica bem como econômica.

Daí, enfrenta-se ainda uma outra realidade dolorosa: a de que até os pesquisadores e cientistas mais célebres dos países em desenvolvimento, quase sempre, devem seu sucesso à associação com grupos internacionais de pesquisa, seguindo os temas em voga, emborá raramente sejam, por si próprios, líderes internacionais nas pesquisas 
básicas ou nas aplicadas. É mais raro ainda encontrar alguém que tenha gerado ou sustentado alguma indústria nacional baseada nos esforços de $P \& D$ próprios.

Focalizando novamente o esquema-modelo, cabe-nos apontar que embora o organograma ali ilustrado tenha alguma validade nas áreas novas, recém-descobertas, ou ainda aquelas que serão dominantes no século vindouro, ele não encontra uma aceitação universal, nem mesmo nos países adiantados, onde se persegue seriamente todas as modalidades de pesquisas. Por exemplo, o eminente dr. David Budivorth (Deputy Director of Corporate Affairs at the Confederation of British Industry) pergunta: "Does technology need more pure science?" e discute brilhantemente a referida polêmica, argumentando inclusive que até a recíproca é verdadeira, ou seja, que muitas vezes as pesquisas tecnológicas apontam caminhos para as pesquisas básicas. Ele conclui: "Pure science research should be justified in terms of quality rather than relevance. Britain's limited resources might nevertheless be better concentrated in fields where practical applications are more likely to be found" (9). Verifica-se também que uma nação como a Grã-Bretanha, correspondendo a $5 \%$ dos gastos de P \& D mundial, debate livremente e preocupa-se com o destino dos recursos aplicados nas suas atividades de pesquisa e desenvolvimento. Então, será que ex-colônias e/ou colônias virtuais não deveriam fazer o mesmo, e com mais rigor ainda?

Mas, apesar de estar evidente e patente que as universidades do Terceiro Mundo não têm condições e capacitação para concorrer, em pé de igualdade, com as instituições de $P$ \& $D$ dos países industrializados, os nossos colegas parecem estar hipnotizados - insistindo em nadar contra a corrente, sem possuir a potência necessária - uma vez que engoliram o molde de pesquisa e pós-graduação (ppg) dos países adiantados, inclusive seus padrões e critérios de produção e avaliação acadêmica, quer do corpo docente como do discente. Assim, em vez de primeiramente praticar e dominar o mais fácil e já conhecido, o que seria um exercício normal e exigido em qualquer outra profissão ou ofício, os "cientistas" do Terceiro Mundo querem logo é estender (supostamente) as fronteiras do conhecimento, sem ter alcançado, dominado ou adaptado as etapas intermediárias.

llustrando melhor o nosso argumento com um exemplo na área de Química Orgânica: não treinamos ou exigimos dos nossos 
pós-graduandos e docentes universitários que dominem primeiro as preparações e produtos de grande utilidade nacional, como por exemplo, ácido salicílico, aspirina, vitaminas A, B ou C, álcool feniletílico e seus ésteres, acetato ou benzoato de benzila, iononas, dapsona, Warfaina ou nitrofurazona, etc. e/ou centenas de milhares de outros processos e produtos de domínio público, e cuja importação e/ou industrialização, por interesses alheios, nos custam divisas, segurança e até ameaçam a própria soberania nacional - como se verifica no comércio de drogas e remédios em nosso país. Pelo contrário, é exigido do nosso mestrando e especialmente dos doutorandos que realizem, na medida do possível, uma contribuição fundamental ou inovadora nas suas especialidades, sendo os resultados medidos, geralmente, em termos de publicações nas revistas especializadas e preferentemente estrangeiras, uma vez que estes são os critérios adotados pelas universidades lá de fora.

Isso parece muito razoável, e até desejável, quando uma nação, grande como a nossa, almeja galgar um status internacional, no que diz respeito a $P$ \& $D$ mundial. Mas, se de um lado, não são asseguradas condições e recursos necessários para um empreendimento desta grandeza, do outro, ninguém tem cuidado de dominar e adaptar as tecnologias e processos que estão no domínio público, há décadas ou mesmo séculos, deixando-os como instrumentos de exploração pelas forças alheias que, assim, controlam aspectos vitais da nossa Ciência, Tecnologia, Economia e, às vezes, a política da própria nação.

. Outrossim, mesmo admitindo a melhor das hipóteses que os nossos governantes, ou algumas generosas fundações internacionais, ou então um milagre inexplicável, tenham proporcionado às nossas universidades as condições de $P \& D$ iguais às das universidades européias e norte-americanas, assim mesmo, teríamos alcançado apenas uma paridade duvidosa, com uma minoria dentro das próprias nações desenvolvidas, uma vez que os esforços de $P$ \& $D$ universitário representam somente 10 a $15 \%$ do total de $P \& D$ daqueles países e correspondem apenas a 6 a $9 \%$ desse total, quando aferidos em termos de dispêndios com suas pesquisas básicas.

Constata-se, desta forma, que enquanto os nossos pós-graduandos, bolsistas e cientistas estão subindo à "torre de marfim" ou estão perdidos nas aventuras "faroesteiras" malogrando em conquistar novas fronteiras; as multinacionais, aqui mesmo, dentro das nossas fron- 
teiras e através de atos corriqueiros e rotineiros, estão industrializando centenas de milhares de produtos, alguns daqueles supracitados, empregando para isso apenas uma ou duas etapas bem-consagradas.

Conseqüentemente, devemos ressaltar que a situação prevalecente em nosso país, especialmente na Quimica Fina e área farmacêutica, não é propícia, seja para um invento novo ou adaptação e produção de um artigo, uma vez que, se, de um lado, enfrentam-se primeiro sérios problemas para a sua produção comercial, devido à falta de insumos e de instalações adequadas na indústria química brasileira, de outro, encontram-se sérios obstáculos na sua comercialização, uma vez que o mercado de emprego intermediário e/ou de consumo final vem sendo tradicionalmente controlados pelos gigantes transnacionais. $E$ aqui convém apontar que estamos erifrentando grupos multinacionais radicados em nosso país, com mercados conquistados, confiança cativada, marcas consagradas, privilégios adquiridos ou mesmo comprados - há muito tempo - e com liderança $\mathrm{e}$ vanguarda, cuja discrepância com a nossa ultrapassa de décadas ou, muitas vezes, alcança até séculos (10). Para termos alguma idéia destes obstáculos, basta recordar as dificuldades e lutas que os interesses brasileiros vêm enfrentando, na área de Informática, para assegurarIhes algum espaço na própria nação. Vale enfatizar que nesta área bem jovem, as desvantagens acima apontadas mal chegam a somar dez anos, seja no que diz respeito ao know-how ou à dominação do mercado brasileiro. Pode-se imaginar, então, as dificuldades reinantes nas áreas já bem-estabelecidas.

Verifica-se, desta forma, que o problema que estamos enfrentando não se resolveria automaticamente apenas pela dominação/adaptação das tecnologias do domínio público, se ao mesmo tempo não tivermos ao nosso alcance medidas adequadas que assegurem, pelo menos, o nosso acesso ao mercado interno brasileiro. Trata-se, então, de uma ação política e não apenas de know-how tecnológico. Isto quer dizer que para mudar a atual situação, dominada pelos interesses externos, são necessárias medidas políticas e legais; estas, de um lado, devem emancipar a nossa indústria e comércio do controle alheio e, de outro, devem assegurar condições para ingresso no setor produtivo de tecnologias endógenas.

Com o intuito de fortalecer os nossos argumentos com alguns dados pertinentes, na Tabela 1 encontra-se o quadro de bolsistas 
mantidos pelo CNPq, tanto no país como no Exterior, durante o período de $1980-1984$. Observa-se que o número de bolsistas no país cresceu de 6.652 para 9.695 no referido período. Supondo que neste período de cinco anos, uma duração superior à média do tempo concedido para conquistar o título de doutor, cada bolsista dominasse

Tabela 1: *Estatísticas relativas às Bolsas e Auxílios do CNPq. (1980-1984)

\begin{tabular}{|c|r|r|r|r|r|}
\hline \multicolumn{6}{|c|}{ A. Total de bolsistas de todas as categorias no país (P) e no Exterior. } \\
(Ext)/Ano/Coordenação \\
\hline Coordenação ** & 1980 & 1981 & 1982 & 1983 & 1984 \\
CEN; (P) & 1.927 & 1.910 & 2.059 & 2.118 & 2.111 \\
(Ext) & 180 & 191 & 209 & 237 & 230 \\
CEG; (P) & 1.172 & 1.139 & 1.340 & 1.376 & 1.557 \\
(Ext) & 171 & 179 & 210 & 210 & 203 \\
CCA; (P) & 1.375 & 1.480 & 1.841 & 1.966 & 2.092 \\
(Ext) & 40 & 60 & 87 & 89 & 86 \\
CCS; (P) & 1.373 & 1.470 & 1.724 & 1.822 & 1.834 \\
(Ext) & 68 & 90 & 152 & 152 & 117 \\
CHS; (P) & 805 & 1.035 & 1.482 & 1.810 & 2.101 \\
(Ext) & 96 & 126 & 253 & 298 & 273 \\
\hline Total; (P) & 6.652 & 7.034 & 8.446 & 9.092 & 9.695 \\
(Ext) & 555 & 646 & 911 & 986 & 909 \\
\hline \multicolumn{7}{|l|}{ B. Dispêndios Anuais em Mil Cruzeiros corrigidos para 1984.} \\
\hline Bolsas (P) & 33.280 .150 & 30.380 .563 & 35.287 .781 & 25.971 .402 & 27.983 .272 \\
(Ext) & 6.080 .903 & 7.140 .149 & 16.256 .815 & 21.951 .117 & 22.899 .281 \\
Auxilios & 15.614 .104 & 15.394 .628 & 16.944 .857 & 15.555 .072 & 20.635 .875 \\
\hline
\end{tabular}

* Adaptado das Tabelas 7. 8 e 11 do "Desenvolvimento Científico e Formação de Recursos Humanos - Desempenho do Setor 1980/84" MCT-CNPq/Brasília, 1985.

** Coordenações: CEN (Ciências Exatas e Naturais); CEG (Ciências da Engenha. ria); CCA (Ciências Agrárias); CCS (Ciências da Saúde); CHS (Ciências Humanas e Sociais). 
e/ou adaptasse apenas um processo ou técnica industrial, já conhecida e no domínio público, e mesmo ignorando a soma cumulativa de bolsistas nestes cinco anos, evitando assim qualquer contagem dupla, teriamos dominado/adaptado de 6.652 a 9.695 técnicas e/ou processos industriais!

Pode-se descontar ainda, visando abrandar a argumentação, os bolsistas da área de Ciências Humanas e Sociais (CHS), seguida das de Saúde (CCS) e Ciências Agrárias (CCA), e mesmo recorrer ao dispositivo de que os esforços dos engenheiros (CEG) apenas complementam os dos cientistas (CEN), ou vice-versa, no que diz respeito à dominação/geração da tecnologia; ainda assim, teríamos assentado à mão quase dois mil (2000) processos/técnicas do domínio público.

Voltando agora a nossa atenção para os bolsistas no Exterior e mantendo a mesma linha de raciocínio, mas com a diferença de que cada um desses bolsistas trouxesse um processo ou uma tecnologia de ponta dos respectivos países adiantados, onde estudaram, teríamos 555 a 909 processos/tecnologias avançadas sob nosso domínio lou pelo menos 180-203 projetos/estudos estratégicos, após os generosos descontos acima concedidos).

Ora, embora o balanço certamente não seja nulo, todos sabemos que apenas uma pequenina fração de nossos cientistas, bolsistas e pós-graduandos tem descoberto um horizonte desconhecido, ou gerado uma tecnologia nova, ou então dominado mesmo uma antiga. Por enquanto, o que se argumenta muito é quanto à falta de "massa crítica" Mas, não é bem isso; o que falta mesmo é responsabilidade, atitude, competência e reflexão. Caso contrário, como é que se explica que a indústria química brasileira, o maior setor industrial tio país, participando com $\sim 5 \%$ do PNB, consegue fazê-lo com apenas 2485 engenheiros químicos e menos do que mil químicos (968)? E, reparem bem, que pouquíssimo deste pessoal ostenta o título de Ph.D. ou mesmo de mestrado!

E aqui vamos adiantar que, nem as universidades ou centros de $P \& D$ governamentais nem as diversas indústrias do setor privado podem, sozinhos, reerguer uma nação dominada pelos interesses externos, se não forem tomadas nela as decisões políticas e providências legais adequadas, visando, de um lado, emancipar o país dos manejos alheios e, de outro, encorajar e incentivar a iniciativa, criatividade, invenção e inovação endógena. Conseqüentemente, deve-se convocar 


\section{ESQUEMA DE P \& D PROPOSTO}




uma "Aliança Democrática" entre o governo, o setor industrial e a Universidade para enfrentar e solucionar o impasse atual.

Entendendo assim e imbuido de muita boa vontade para colaborar, propomos abaixo um esquema alternativo de $P \& D$, seguido de algumas sugestões pertinentes no que diz respeito aos diversos segmentos envolvidos. Mas antes, talvez precisemos recordar o clássico, mas excelente, exemplo do Japão, que, embora ridicularizado e taxado de imitador num passado não tão distante, hoje goza de muita fama e respeito em. $C \& T$ !

Embora o esquema ilustrado dispensasse quaisquer comentários adicionais, gostaríamos de salientar as interações recíprocas ali indicadas entre o setor produtivo, centros de $P$ \& $D$ governamentais $e$ privados, universidades e o Instituto Nacional de Propriedade Industrial (INPI), este último depositário de $>15$ milhões de patentes e outros documentos técnicos, que deverão ajudar e socorrer os nossos pesquisadores nas tarefas de $P \& D$ propostas. Ressaltamos também que, nesta proposta, as linhas de pesquisas básicas são geradas tanto pelas referidas interações quanto pelos problemas enfrentados, seja na dominação, adaptação e aperfeiçoamento dos processos conhecidos ou de invenções realizadas ou apenas malogradas. E para apaziguar os ânimos dos químicos fundamentais surpreendidos e/ou ofendidos pela presente proposta, fica a convite - a título de simples ilustração, mas invocando a sua criatividade nas pesquisas puras para melhorar o atual método de carboxilar o fenol, visando obter ácido salicílico, seus ésteres ou aspirina, ou então desenvolver um processo novo para produção de qualquer uma das centenas de miIhares de produtos relacionados nos cadastros da Abiquim, Abifarm e Conselho de Desenvolvimento Industrial (CDI).

Enfim, chegamos às sugestões gerais bem como concretas:

1. No que diz respeito à Universidade: - Esta instituição deve tentar, na medida do possível e nas áreas prioritárias, alcançar as fronieiras dos aspectos teóricos do atual conhecimento humano. Mas nas áreas experimentais e especialmente aquelas susceptíveis à exploração econômica, deve-se também dominar em esforços conjuntes conforme proposto no esquema supra-ilustrado, tudo o que a nação precisa para o seu parque industrial, seja para suprir a demanda interna 
ou para exportação. Para isso, é necessário que essa instituição modifique os seus critérios ambos para a escolha dos temas e projetos a serem pesquisados, visando dissertação ou tese de mestrado e doutorado, e para avaliação dos discentes bem como docentes orientadores. llustrando melhor, um mestrando poderá perfeitamente abordar um projeto simples como, por exemplo, a preparação de acetato e/ou benzoato de benzila. Após comparar os diversos métodos de sua produção disponiveis no domínio público, pela análise dedutiva baseada na disponibilidade dos insumos, seus preços, facilidade, complexidade e/ou periculosidade dos processos envolvidos, subprodutos e seu valor, instalações necessárias, gastos energéticos, efeitos nocivos de detritos ou a sua ausência, etc, deve-se executar os melhores métodos dentre os escolhidos; primeiro, na bancada de laboratório e, posteriormente, junto com um engenheiro químico, na escala piloto e, finalmente, na escala comercial. E como o projeto escolhido foi um dos constantes das prioridades nacionais, logo estará dominado um, dois ou mais processos e colocados no parque industrial os respectivos produtos. Além disso, se, de um lado, habilita-se tanto os mestrandos em Química quanto os de Engenharia Química, do outro, possibilita-se 0 ingresso de pessoal qualificado no setor produtivo nacional, que é sabidamente sem tradição no $P \& D$ endógeno.

Para o doutoramento, podemos sugerir dominação dos produtos/processos mais complexos e envolvendo etapas múltiplas, como exemplificado pela síntese de vitamina $A, C$ ou de complexo $B_{6}$. Todavia, deve-se frisar que os exemplos citados são apenas para estabelecer o argumento, mas não limitam e nem esgotam o escopo da sugestão. Além disso, deve-se também tentar entender o know-why de tantas tecnologias importadas, cujo know-how apenas foi comprado, visando tanto a dominação das atuais, quanto o desenvolvimento de novas invenções. $E$ ai vamos enfrentar os problemas reais do mundo tecnológico, constatando que, na maioria dos casos, os nossos empresários não podem falar do assunto, seja devido às restrições de sigilo na compra de "pacotes tecnológicos" ou pela ignorância dos processos envolvidos.

Outrossim, esta proposta certamente exige interações mútuas, ativas e produtivas, entre os químicos e engenheiros químicos, que por sua vez terão repercussões nos respectivos currículos, ambos de graduação e pós-graduação, necessitando de modificações adequadas. 
E para pacificar aqueles, que a esta altura já estão constatando o abastardamento dos títulos tradicionais, sugerimos que se pode arranf jar perfeitamente um novo rótulo para as especialidades propostas; não importando os nomes e carimbos, mas, sim, a competência e conteúdo!

Obviamente, este novo tipo de desempenho dos discentes e docentes deve ser avaliado por critérios novos, no que diz respeito às atividades de dissertação, tese e publicações: em vez de avaliação convencional feita pelos resumos, comunicações, cartas e artigos publicados nas revistas acadêmicas, deve-se agora julgar pelos projetos, produtos, processos, métodos e técnicas, etc, dominadas ou adaptadas e descritas detalhadamente nos respectivos relatórios, cujo resumo ou inteiro teor pode ou não ser publicado, dependendo do interesse, ou não, na sua. ampla divulgação. Além disso, os aprimoramentos bem como o desenvolvimento de novos processos, produtos, técnicas, etc, ou seja, invenções e inovações merecem, naturalmente, um reconhecimento e participação maior dos inventores/inovadores envolvidos.

Finalmente, embora tenhamos ilustrado os nossos argumentos com exemplos na área da Síntese Orgânica, isso não significa uma restrição ou limite natural para a abrangência geral da proposta, uma vez que pode-se arranjar perfeitamente analogias igualmente válidas nos outros ramos do saber humano. $E$, aqui, enfatizamos novamente que destas pesquisas vão surgir muitos desafios tanto de ordem prática quanto de caráter acadêmico, exigindo busca de novos conhecimentos básicos e fundamentais, testando severamente a capacidade, a competência e a criatividade dos nossos pesquisadores, bolsistas e famosos cientistas.

Diante do exposto e resumindo, podemos concluir que a Universidade deve:

a) Continuar perseguindo as fronteiras dos aspectos fundamentais do saber humano, através de cursos avançados, utilizando aulas, seminários, debates, conferências, etc.

b) Começar, também, a ajudar nas tarefas de dominar e adaptar as tecnologias do dominio público, que ainda são explorados em nosso país apenas pelos interesses alheios à nossa nação.

c) Conseqüentemente, modificar os seus critérios e preferências tanto para escolha de assuntos, temas e projetos para dissertação ou 
tese de mestrado e doutorado - que doravante devem ser ligados às prioridades nacionais - quanto para avaliação do desempenho discente e docente.

d) Realizar uma interligação eficaz entre os respectivos departamentos de Ciências, de Engenharias, centros de $P$ \& $D$ nacionais e o setor produtivo, visando viabilizar, conjuntamente, os intentos do item $b$.

e) Efetuar modificações adequadas nos respectivos currículos de Engenharia e Ciências Puras, ambos ao nível de graduação e pós-graduação, visando atender às necessidades dos itens anteriores.

2. No que diz respeito ao setor industrial, este setor deve:

i) Dissociar-se, progressivamente, da simbiose e do crescimento dependente das multinacionais, gerado pelo modelo associativo adotado no passado.

ii) Esforçar-se, de fato, para aprender como sobreviver e crescer, progredir e prosperar, baseado nos esforços próprios ou, então, pelo menos, naqueles realizados na sua nação.

iii) Para tanto, começar a associar-se, imediatamente, seja com os centros de $P \& D$ estatais ou universidades, ou instalar os seus próprios laboratórios de $P \& D$, ou então organizar consórcios patrocinados pelos diversos membros desse setor, buscando soluções, inovações, processos, produtos, técnicas e serviços, etc, para o bem do país e consumo da nação.

3. No que diz respeito aos dirigentes governamentais, cabe-thes tomar todas as decisões, medidas e providências necessárias, sejam políticas, econômicas ou legais, para viabilizar os verdadeiros propósitos e intentos desta proposta, que resumidamente são: emancipar a nação dos controles e manejos alheios e garantir, pelo menos, o mercado interno para os produtos, bens e serviços gerados e produzidos no país, pelas tecnologias endógenas.

Entre estas medidas do nosso governo, gostariamos de constátar as seguintes:

I. Intensificação $(2-2,5 \%$ do PIB) de suas obrigações tradicionais de proporcionar os recursos financeirus, conceder incentivos fis- 
cais e/ou isenção alfandegária e providenciar demais condições, visando frutificar as atividades de $P$ \& $D$ realizadas no país.

II. Estabelecimento de uma interligação eficiente entre os diversos componentes vitais para o pleno êxito da Ciência e Tecnologia nacional, a saber, o próprio governo, centros de $P$ \& $D$ estatais ou privados (nacionais), universidades, o INPI e o setor produtivo, conforme ilustrado no esquema proposto.

III. Elaboração das prioridades nacionais de $P$ \& D, de acordo com a "demanda nacional" indicada no referido esquema e em consulta conjunta com os diversos segmentos nacionais envolvidos, seja nas atividades de P \& D ou na sua exploração; como destacados no item anterior (II).

IV Consolidação dos núcleos já existentes e estabelecimento de novos centros de $P$ \& $D$, nas áreas prioritárias e/ou estratégicas, sejam eles estatais, consórcios do setor privado (nacional) ou nas universidades, com a incumbência prioritária de dominar e/ou adaptar os processos no domínio público, visando industrializar os bens, produtos, serviços, etc, de interesse e urgência nacional.

V. Incentivos aos pesquisadores, inventores e suas equipes, dando-Ihes condições de $P$ \& $D$, participação nas tecnologias dominadas, adaptadas, aprimoradas ou desenvolvidas, etc. e, inclusive recursos e condições para fundar suas próprias empresas, especialmente quando não se encontra uma empresa nacional para explorar o know-how gerado por eles.

Isso iniciará a tradição de empresas baseadas em P \& D endógeno e significará ingresso de pessoal altamente qualificado no setor produtivo brasileiro, o que não vem acontecendo normalmente.

VI. Proibição do pagamento de royalty, direitos de licenciamento ou reembolsos similares e remessas de lucros para produtos, bens e serviços, cujo know-how já se encontra no domínio público, não permitindo doravante a sua produção pelos interesses alheios, no âmbito da nação, e, especialmente, para entrada no nosso mercado interno, quando os mesmos puderem ser produzidos pelos esforços nacionais, conforme o desempenho dos centros de $P \& D$ acima referidos ou de pesquisadores/inventores isolados. 
VII. Coordenação das atividades de $P \& D$ aqui referidas e especialmente a sua frutificação, no que diz respeito à ação governamental.

Finalmente, apontamos alguns dos grandes adversários da presente proposta, a saber: os cientistas influentes, mas pertencentes aos clubes internacionais; os docentes/pesquisadores acomodados; os empresários comprometidos e dependentes do processo externo; extensa infiltração, grande influência e forte pressão das corporações multinacionais, etc. Econcluímos fazendo votos que as classes politicamente esclarecidas da nossa sociedade, as associações profissionais, os docentes e discentes universitários, as sociedades científicas e, especialmente, os legisladores e administradores percebam a gravidade dos desafios e saibam como resguardar os interesses da nação.

\section{Agradecimentos}

Agradeço a todos os colegas e amigos que tiveram a paciência de ler o trabalho original e fizeram observações/correções construtivas.

\section{BIBLIOGRAFIA}

MAHAJAN, J. R. e ARAÚJO, H. C. Empenho da Indústria nas Atividades de Pesquisa $e$ Desenvolvimento ( $P$ \& D) no Brasil e nos Paises Adiantados, Focalizando o Setor Químico. Química Nova, São Paulo, 7 (3), 168-174, 1984.

MAHAJAN, J. R. A Pesquisa Pura e Aplicada no Brasil e no Mundo, Ressa/tando as Ciências Quimicas. Ciência e Cultura, São Paulo, 37 (5), 729-734, 1985.

BOWEN, E. Education: Schooling for Survival - U.S. Corporations Move en Masse into the Learning Business. Time - The Weekly News Magazine, Time Inc., Chicago, 125 (6), 42-43 (11.02.1985).

Ministério da Educação - Secretaria da Educação Superior. Nova Universidade - Programa de Apoio à Educação Superior. Editada pela Assessoria de Comunicação da SESU, Brasilia, 1985.

MEC-SESU-CAPES. III Plano Nacional de Pós-Graduação - 1986/1989. IVersão Preliminar). CAPES, Brasilia, 1986.

SUCUPIRA, N. (Relator) e outros. Pareceres Básicos do Conselho Federal de Educação: a) Parecer no 977/65. Assunto: Definição dos Cursos de Pós-Graduação; b) Parecer n? 77/69. Assunto: Normas do Credenciamento dos Cursos de Pós-Graduação. Na Coletânea Ensino Superior - Legislação e Jurisprudência, 2a. edição, por Guido Ivan de Carvalho, Rio de Janeiro, 1969. 
Ref. 6a: Um Exemplo de Pós-Graduação: A Norte-Americana; página 156.

Facts \& Figures for Chemical R \& D. Chemical Engineering News, Washington, D.C., 63 (29), 28-56, 1985; veja também "Funds for R \& D are up 17\% in Administrations Budget Proposal"', ibid., 64 (7). 9, 1986; ibid., 63 (7) 1985.

BUDWORTH, D. Does Technology Need More Pure Science? New Scientist, London, 105 (1438), 12-15 (10.01.1985).

MAHAJAN, J. R. Química Fina, Universidades Brasileiras, Empresa Nacional, Politica de C \& T e Reserva de Mercado etc. Enviado para publicação.

- Adaptado da versão preliminar, com este mesmo título. MAHAJAN, J. R. Revista de Química Industrial, Rio de Janeiro, 55 (650): 8-18, junho, 1986. 


\section{FICHA CATALOGRAFICA}

MAHAJAN, Jaswant Rai. Uma Proposta Alternativa de Pesquişa, Pós-Graduação e Desenvolvimento, Especialmente nas Ciências Químicas, Sobretudo para o Brasil e o Terceiro Mundo em Geral. Revista da Universidade de São Paulo. São Paulo, (4): p. 87 - 106, março de 1987. 